\title{
Ferropenia sin anemia, más que un hallazgo de laboratorio
}

\section{Ferropenia without Anemia, more than a Laboratory Finding}

Recepción: 07/05/2018 | Aceptación: 05/07/2018

\author{
Daniel Martín Arsanios \\ Universidad de La Sabana, Colombia \\ SAMUel SERRANo \\ Universidad de La Sabana, Colombia \\ BAYRon EsPINEL \\ Universidad de La Sabana, Colombia \\ Elías Quintero \\ Universidad de La Sabana, Colombia \\ María José Rincón \\ Universidad de La Sabana, Colombia \\ Alirio Bastidas Goyes \\ Universidad de La Sabana, Colombia
}

a Correspondencia: danielmartin_2@hotmail.com

Cómo citar: Martín Arsanios D, Serrano S, Espinel B, Quintero E, Rincón MJ, Bastidas Goyes A. Ferropenia sin anemia, más que un hallazgo de laboratorio. Univ. Med. 2018;59(4). doi: https://doi.org/10.11144/Javeriana.umed59-4.ferr

\section{RESUMEN}

El déficit de hierro sin anemia se encuentra presente en diversas patologías de la práctica clínica; sin embargo, se conoce poco sobre la importancia, las complicaciones y los beneficios de su tratamiento. Este artículo describe la evidencia actual sobre distintas vías fisiopatológicas, abordaje y tratamiento de las principales patologías relacionadas con la ferropenia sin anemia. Para ello se realizó una búsqueda completa y actualizada de la literatura científica en Medline, OVID, Lilacs, SciELO y EMBASE utilizando una estrategia definida con términos $\mathrm{MeSH}$ y no $\mathrm{MeSH}$, limitado a español e inglés.

Palabras clave

deficiencia de hierro; anemia; hierro.

\section{ABSTRACT}

The deficit of iron without anemia is present in frequent pathologies of clinical practice, however, little is known about the importance, complications and benefits of the treatment. In this article, we describe an uptodate of the physiopathological pathways, the approach and treatment of the main pathologies related to iron deficiency without anemia. Methods; A complete and updated search of the scientific literature was made, in Medline, OVID, Lilacs, SciELO, EMBASE using a strategy defined with MeSH terms and not MeSH, limited to Spanish and English.

Keywords

iron deficiency; anemia; iron. 


\section{Introducción}

Se estima que el déficit de hierro se encuentra presente en un tercio de la población mundial (1). Este se ha relacionado con múltiples afectaciones en todos los sistemas, con un número no despreciable de artículos que muestran las diversas complicaciones, síntomas $\mathrm{y}$ afecciones de la calidad de vida en pacientes con enfermedades digestivas, hematológicas, renales, entre otras. En un estudio realizado en Holanda, con personas sanas, donantes de sangre sin anemia, se tomó como medida indicadora de déficit de hierro concentraciones de protoporfirina $>100 \mu \mathrm{mol} / \mathrm{mol}$ y se halló que de 5280 personas, en el 6,9\% de los hombres y el 9,8\% de las mujeres se presentaba ferropenia sin anemia (2). En el presente artículo se busca caracterizar las afectaciones, el impacto, el mecanismo, el abordaje y el tratamiento de las diferentes complicaciones derivadas del déficit de hierro sin evidencia de anemia.

\section{Metodología}

Se realizó una búsqueda completa y actualizada de la literatura científica, en Medline, OVID, Lilacs, SciELO, EMBASE utilizando una estrategia definida con términos $\mathrm{MeSH}$ y no $\mathrm{MeSH}$, en español e inglés, sin límite de año, en la cual participaron 5 investigadores. Se construyó una base de datos con los artículos que abarcaran la temática propuesta y que relacionaran la ferropenia sin anemia con cada una de las enfermedades seleccionadas por cada sistema. Estas enfermedades se escogieron basándose en la importancia en la práctica clínica, la cantidad y la calidad de la evidencia disponible para cada patología.

\section{Hallazgos en laboratorio}

Los depósitos de hierro se pueden evaluar tanto con métodos directos como indirectos, no excluyéndose los unos de los otros, dado que el adecuado abordaje de la homeostasis del hierro se da mediante la combinación de hallazgos de laboratorio y no de un único resultado (3). Los métodos directos, en su mayoría, son sensibles y específicos para evaluar el estado de hierro en el cuerpo (dentro de estos encontramos: la biopsia y el aspirado de médula ósea) y por medio de estos se obtiene una evaluación semicuantitativa de los depósitos de hierro a través de la tinción de la hemosiderina de los macrófagos con Azul de Prusia.

Así se determina la proporción y la morfología de sideroblastos, que se correlacionan con el aporte de hierro a la médula ósea y con las características generales de la hematopoyesis (3). No obstante, este es un método que en la práctica clínica tiene poca utilidad para evaluar la homeostasis del hierro, dado que es invasivo; de igual manera, en cuanto a los fines investigativos, el estudio de la médula ósea no es reproducible, dada la variabilidad entre observadores, las muestras inadecuadas y la poca correlación con la respuesta a la terapia con hierro $(4,5)$. Todo esto, junto a que no hay una indicación de realizar estos métodos diagnósticos con solo tener hipoferritinemia o sospecha de ferropenia explica los pocos estudios realizados con estos métodos diagnósticos y por qué no se encuentran estudios que evalúen el estado de hierro en pacientes sin anemia con estas estrategias.

Por otro lado, los métodos indirectos son menos sensibles y específicos, aparte de que son alterados por enfermedades infecciosas $\mathrm{e}$ inflamatorias crónicas por medio de la hepcidina; pero, por no ser invasivos y más fáciles de interpretar en comparación con los métodos directos, son los más utilizados (figura 1). 


\section{Figura 1}

Hallazgos paraclínicos directos e indirectos

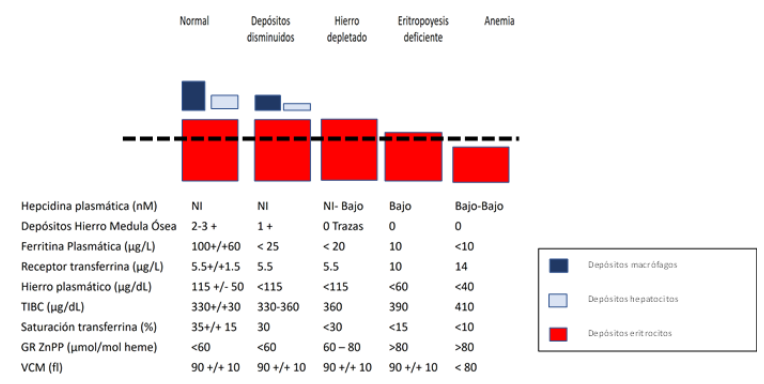

Fuente: imagen realizada por Daniel Martin et al., basada en Brittenham GM. Disorders of iron homeostasis [internet]. En Hematology:

Basic Principles and Practice. 7th ed.

Philadelphia: Elsevier; 2013. p. 437-49.

Antes de la aparición de la anemia franca $(\mathrm{Hb}<12 \mathrm{~g} / \mathrm{L} \quad$ o $13 \mathrm{~g} / \mathrm{L}$ en mujeres $\mathrm{y}$ hombres, respectivamente), suceden una serie de alteraciones en los depósitos y en las células hematopoyéticas, comenzando con la disminución de la ferritina, la cual es la manifestación más temprana de este déficit. Si persiste el bajo aporte o absorción, se reduce la entrega de este a los tejidos y aumenta la protoporfirina de zinc, así como el receptor de transferrina, ya que la síntesis de receptores de transferrina aumentan de forma inversamente proporcional a la magnitud del déficit de hierro. En este punto, los valores de hemoglobina, volumen corpuscular medio (VCM) y hemoglobina corpuscular media (HCM) continúan dentro de límites normales, lo cual se ha denominado deficiencia de hierro sin anemia (6). También se puede encontrar disminución de la concentración de hemoglobina y reducción del contenido de la hemoglobina media. Si persiste la deficiencia de hierro, el VCM y la HCM empiezan a disminuir progresivamente, y a esta fase en la cual se ve afectada la hematopoyesis se le conoce como deficiencia de hierro con microcitosis o hipocromía (6). El paso siguiente es la anemia por déficit de hierro, en la cual se encuentran afectadas las cantidades de hemoglobina.

La ferritina es las más estudiada y usada en la práctica clínica, dada su sensibilidad y especificidad. Fue descubierta en 1936 por M.
V. Laufberger, científico francés que aisló esta proteína en el bazo de un caballo. Esta proteína la componen dos tipos de subunidades, una $\mathrm{H}$ y otra L. Aunque el rol de la ferritina más estudiado es el del depósito de hierro, se sabe que está involucrada en el transporte de hierro, posee un mecanismo antiinmune mediado principalmente por la ferritina $\mathrm{H}$ y el receptor de células $\mathrm{T}$ con dominios de mucina e inmunoglobulina 2 (TIM-2), está relacionado con un cininógeno de alto peso molecular (HK) con el cual interacciona y desencadena vías que promueven la vasodilatación y liberación de moléculas proangiogénicas, así como otros mecanismos que desempeñan un papel importante en el cáncer, respuesta inflamatoria sistémica, entre otros (7).

En cuanto a la relación entre la ferritina y el déficit de hierro, como se puede evidenciar en la figura 1, incluso antes del desarrollo de la anemia ya hay cambios importantes en los niveles de ferritina. La medición en sangre es muy específica cuando no se mide en pacientes con enfermedades inflamatorias crónicas (8), y es el parámetro más fuerte y útil para evaluar el déficit de hierro. Se ha propuesto hablar de déficit de hierro cuando la ferritina se encuentra por debajo de $30 \mathrm{ng} / \mathrm{ml}$; no obstante, aunque se obtenga una sensibilidad y especificidad del 92\% y del $98 \%$, respectivamente, no es un punto de cohorte que haya sido adoptado mundialmente, no se ha evaluado en paciente ancianos, con múltiples comorbilidades o enfermedades inflamatorias, por lo que se debe ser cauteloso en la interpretación de estos valores (9).

Los reticulocitos, al igual que la ferritina, presentan alteraciones mucho antes a la disminución de VCM, HCM y hemoglobina de los eritrocitos (10). Cambios en la coloración de los reticulocitos son una forma rápida de detectar la deficiencia de hierro subclínico en pacientes no anémicas premenopáusicas. Dentro de los parámetros evaluados se encuentra el contenido de hemoglobina reticulocitario, el cual es el producto entre la concentración de hemoglobina y el tamaño celular. Se ha demostrado que este parámetro de laboratorio está alterado desde estadios tempranos, principalmente desde la deficiencia de hierro latente (ferritina $<30 \mathrm{ng}$ / 
$\mathrm{ml}$, aumento del receptor soluble de transferrina $>8,3 \mu \mathrm{g} / \mathrm{ml}$ y $\mathrm{TIBC}>390 \mu \mathrm{g} / \mathrm{dL} ; \mathrm{p}<0,001)$ (11).

En este estudio también se evidenció una diferencia significativa entre los pacientes normales y aquellos con deficiencia de hierro prelatente (ferritina $<30 \mathrm{ng} / \mathrm{ml}$ ) $\mathrm{p}<0,05$ así como una diferencia estadísticamente significativa entre ambos estadios (11). Sin embargo, la mejor sensibilidad y especificidad fue de $\tan$ solo $73,9 \%$ y 73,3\%, respectivamente; estos datos se tomaron de una población en la cual se excluían los pacientes con una VCM mayor o igual de $100 \mathrm{fL}$, ya que la sensibilidad llega a disminuir hasta $60,7 \%$, abarcando a los pacientes con este VCM (9). Hay que tener en cuenta que la población evaluada era joven con una media de edad de 16,9 $\pm 1,8$, atletas, sanos, lo cual no es el común denominador (11).

\section{Sistema cardiovascular}

Se ha estudiado ampliamente la anemia en falla cardiaca (FC) y se ha demostrado que aumenta la mortalidad dos veces en comparación con los pacientes sin anemia (figura 2). Sin embargo, a diferencia de la anemia, la relación entre el déficit de hierro y la FC es un tema relativamente nuevo y del cual en la última década se ha profundizado en los mecanismos fisiopatológicos, consecuencias y tratamiento de estos pacientes. Aproximadamente, el 20\% de los pacientes con FC presenta déficit de hierro $(12,13)$. En un estudio realizado con 955 pacientes con FC y fracción de eyección reducida $(<45 \%)$ se encontró que el $15 \%$ de los pacientes sin anemia tenían algún test positivo para el déficit de hierro (14).

\section{Figura 2}

Déficit de hierro en falla cardiaca. La disminución en la expresión del factor intestinal inducido por hipoxia (HIF)-2 se relaciona con la disminución en la expresión del citocromo duodenal b (Dcyt-b) y el transportador divalente de metales 1 (DMT1), lo cual se asocia con la disminución en la captación de hierro. También se evidencia una disminución de la ferroportina que no se vincula directamente con la hepcidina

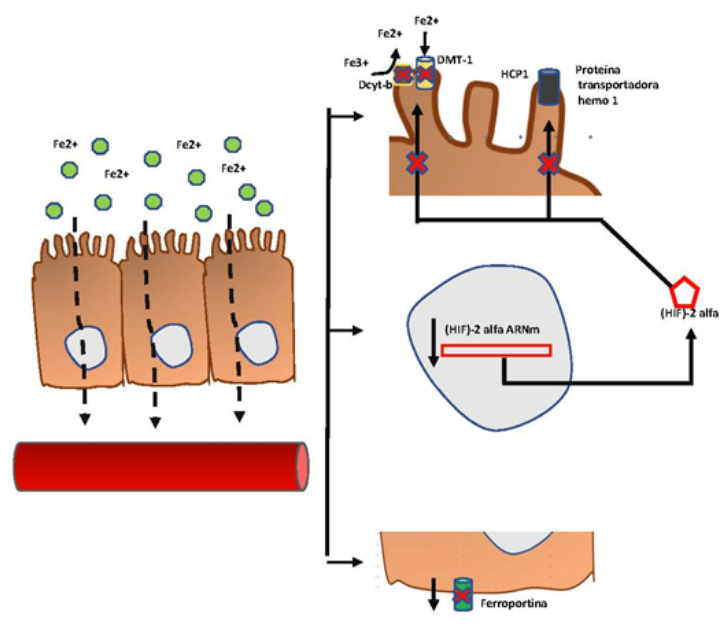

De igual manera, en otro estudio (15) realizado en Polonia en 544 pacientes con FC sistólica y fracción de eyección reducida estable, en el cual se definía deficiencia de hierro como ferritina $<100 \mathrm{mg} / \mathrm{L}$ o ferritina $\geq 100 \mathrm{mg} / \mathrm{L}$, pero $\leq$ $300 \mathrm{mg} / \mathrm{L}$ con saturación de transferrina < $20 \%$, la prevalencia de déficit de hierro sin anemia fue de $32 \pm 4 \%$. Se sabe que el déficit de hierro está relacionado con aumento del riesgo, empeoramiento de los síntomas e incluso la mortalidad en algunas enfermedades cardiovasculares, dentro de las que se encuentra la enfermedad coronaria y la FC. De igual modo, tiene un impacto negativo en los pacientes con cirugías cardiacas (trasplante cardiaco y otro tipo de cirugía cardiaca).

\section{Enfermedad coronaria}

Existe una relación proporcional entre las bajas concentraciones de transferrina y ferritina con un aumento en el riesgo de presentar enfermedad 
coronaria, aun cuando este es independiente a la presencia de anemia (16). Existen dos estudios en los cuales se demuestra una alta prevalencia de cardiopatía isquémica en los pacientes con déficit de hierro: el primero realizado por Jankowska et al. (15), en el cual se reportaba una prevalencia del $48 \%$ en pacientes con enfermedad coronaria estable que iban a ser llevados a cirugía cardiaca, y el segundo realizado por Oona Meroño et al. (17), quienes reportaban una prevalencia del 61\%. No obstante, el último estudio definió el déficit de hierro como ferritina $<100 \mathrm{ng} / \mathrm{mL}$ o ferritina $<800 \mathrm{ng} / \mathrm{mL}$ más transferrina $<20 \%$, lo cual no está acorde con las definiciones de déficit de hierro utilizadas en la mayoría de estudios (ferritina $<100 \mathrm{mg} / \mathrm{L}$ o ferritina $\geq 100 \mathrm{mg} / \mathrm{L}$, pero $\leq 300 \mathrm{mg} / \mathrm{L}$ con saturación de transferrina $<20 \%)$.

No se conoce hasta el momento el mecanismo fisiopatológico que explique la relación entre ferropenia y enfermedad coronaria. Oona Meroño et al. (17) encontraron dos aspectos que pueden plantear un mecanismo inflamatorio como el causante de desarrollo de enfermedad coronaria: el primero es la diferencia significativa que existe entre los pacientes con déficit de hierro y el grupo placebo, dado que en el primer grupo hay un mayor número de pacientes con diabetes, hipertensión y tabaquismo, todos estos relacionados con un componente inflamatorio ya estudiado ampliamente, y el segundo, la correlación entre inflamación y ferropenia, donde se muestran cómo hay una relación significativa entre los niveles de interleucina 6 (IL-6), proteína $\mathrm{C}$ reactiva y niveles bajos de hierro sérico.

Esto último también fue evidenciado por Ching-Hui Huang et al. (18), quienes investigaron el valor pronóstico de la concentración de hierro sérico en relación con la fracción de eyección del ventrículo izquierdo y el puntaje de riesgo TIMI en pacientes posinfarto agudo de miocardio. Fue importante la relación significativa entre los niveles bajos de hierro sérico y un mayor riesgo de infarto agudo de miocardio, así como un menor porcentaje de recuperación $(<10 \%)$ de la fracción de eyección del ventrículo izquierdo tras la angioplastia.
Adicionalmente, fue significativa la relación entre hierro disminuido y concentraciones altas de IL-6 en pacientes con infarto agudo de miocardio con elevación del ST (segmento ST), así como una relación inversamente proporcional entre el hierro sérico y el puntaje TIMI ( $\mathrm{p}=$ 0,002).

Por último, se destacan los resultados del estudio realizado por Ewa A. Jankowska et al. (19), en el cual se utilizó el aspirado de médula ósea para evaluar el déficit de hierro en personas con EC estable. Se encontró que el receptor soluble de transferrina, la transferrina y el receptor de eritropoyetina se correlacionaban con déficit de hierro, a diferencia de la ferritina sérica. De ahí que sea el receptor soluble de transferrina el de más fuerte asociación (área bajo la curva $=0,876 \pm 0,048$, siendo el punto más eficaz $\geq 1,32 \mathrm{mg} / \mathrm{l}$, con una sensibilidad del $67 \%$ y una especificidad del $97 \%$ ). Así mismo, encontraron que el $43 \%$ de los diagnosticados con déficit de hierro no cursaban con anemia.

\section{Falla cardiaca}

Al usar los criterios de deficiencia de hierro absoluto y relativa (ferritina $<100 \mu \mathrm{g} / \mathrm{L} \mathrm{y}$ ferritina 100-299 $\mu \mathrm{g} / \mathrm{L}$ más transferrina $<20 \%$, respectivamente) de 546 pacientes con falla cardiaca, el $32 \%$ presentaba ferropenia sin anemia, siendo el déficit de hierro un desenlace negativo independiente a la presencia de anemia (15). En un estudio prospectivo-observacional, realizado por Inês Rangel et al. (20), se incluyeron pacientes con falla cardiaca estable con fracción de eyección del ventrículo izquierdo reducida $(<45 \%)$ y cuyo desenlace compuesto primario fue mortalidad total y eventos no fatales cardiovasculares, de 127 pacientes con déficit de hierro, el $74 \%$ no presentó anemia y durante un periodo de 225 días el $24 \%$ de los pacientes con déficit de hierro desarrolló el desenlace compuesto primario; mientras que solo el $5 \%$ en aquellos sin déficit de hierro (21).

Hasta el momento no existe un mecanismo fisiopatológico que explique completamente la anemia en falla cardiaca. Se sabe que es 
multifactorial, pero hay contradicciones entre distintos artículos sobre cuál es el mecanismo más frecuente. Por ejemplo, Nanas et al. (22) estudiaron pacientes con anemia y falla cardiaca en estadio final y documentaron la presencia de anemia por déficit de hierro en el $73 \%$ de los casos.

El déficit de hierro puede ser absoluto, cuando los depósitos están agotados, o puede ser funcional, cuando hay una alteración en el metabolismo del hierro, incluyendo los procesos inflamatorios (23). En un estudio realizado en ratones se buscó evaluar los mecanismos fisiopatológicos que llevaban al desarrollo de ferropenia. Se encontró que la expresión del factor intestinal inducido por hipoxia-2, encargado de la regulación del citocromo duodenal $\mathrm{b}$ y el transportador divalente de metales 1 se encontraba disminuida en los pacientes con falla cardiaca, e interesantemente, a pesar de que los niveles de hepcidina fueran bajos, había una disminución en la expresión de la ferroportina, lo cual se correlacionaría con una alteración generalizada de los sistemas reguladores del hierro. Se cree que el factor gatillo de esta teoría es el estrés oxidativo, el cual disminuye la expresión de factor intestinal inducido por hipoxia-2 alfa (24). Otro hallazgo llamativo es la relación entre caquexia y el desarrollo de ferropenia, pues se sabe que la caquexia es un indicador de inflamación, y en estos animales la presencia de esta se correlacionaba con ferritina baja, hierro disminuido y baja capacidad total de fijación del hierro, lo cual se encuentra a favor de que todo lo anterior esté mediado por un mecanismo inflamatorio.

La administración de hierro en pacientes con falla cardiaca e inicio conjunto con eritropoyetina en pacientes con anemia $(25,26,27,28,29,30,31)$ no mostró ningún beneficio con el suministro de darbepoetina alfa vs. placebo, tanto en los desenlaces primarios (muerte por cualquier causa u hospitalización por empeoramiento de la falla cardiaca) como en los secundarios; por el contrario, aumentó la tasa de eventos tromboembólicos y el riesgo de accidente cerebrovascular isquémico. De igual manera, distintos estudios en pacientes con anemia sin el uso de eritropoyetina mostraron que hubo mejoría en los niveles de hemoglobina, clase funcional y calidad de vida (32).

Desde el estudio FERRIC-HF (33) se evaluó el beneficio de la aplicación intravenosa de hierro, incluyendo pacientes no anémicos $(\mathrm{n}=17)$ con déficit de hierro (ferritina $<100 \mathrm{~g} / \mathrm{L}$ o entre $100 \mathrm{~g} / \mathrm{L}$ y $300 \mathrm{~g} / \mathrm{L}$ con transferrina < $20 \%$ ), quienes encontraron una mejoría en la duración del ejercicio, transferrina, ferritina y clase funcional. Si bien el grupo con anemia evidenciaba parámetros similares a los pacientes no anémicos, los primeros mostraron mejoría en el consumo pico de oxígeno y hemoglobina, lo cual sugiere que el principal efecto del hierro en pacientes sin anemia es sobre la calidad de vida.

De forma similar, el estudio CONFIRM-HF (6) evaluó el suministro de hierro carboximaltosa vs. placebo en pacientes con falla cardiaca con fracción de eyección reducida, clase funcional NYHA II-III y hemoglobina $<15$ g/dL. Se encontró una mejoría en la prueba de caminata de 6 min a la semana 24 e incluso a la semana 52, así como una disminución en el riesgo de hospitalización por descompensación de falla cardiaca en el grupo de pacientes que recibieron hierro.

El estudio EFFECT-HF (34), con una metodología similar a los anteriores, comparó la administración de hierro carboximaltosa vs . placebo en 174 pacientes con falla cardiaca con fracción de eyección reducida, estables, NYHA II-III con péptido cerebral natriurético o porción amino-terminal del propéptido natriurético tipo B $>100 \mathrm{pg} / \mathrm{mL} \mathrm{o}>400 \mathrm{pg} / \mathrm{mL}$, respectivamente, y déficit de hierro con hemoglobina $<15$ sin necesidad de transfusión inmediata. El desenlace primario fue el cambio de pico de oxígeno desde el inicio hasta la semana 24.

Respecto al desenlace primario, se evidenció una mejoría significativa en el grupo de hierro $(\mathrm{p}=0,02)$, así como en la calidad de vida y clase funcional. Por el contrario, en los desenlaces secundarios no se encontró una diferencia significativa en cuanto a ventilación minuto/ pendiente de producción de dióxido de carbono y la tasa de trabajo máximo. En este momento 
se encuentra en curso un estudio aleatorizado, doble ciego controlado, en pacientes con falla cardiaca aguda en que se compara el uso de hierro carboximaltosa vs. placebo (AFIRM-AHFNCT02937454). En cuanto al uso de hierro oral, en el estudio IRONOUT HF (35) se comparó hierro polisacárido vs. placebo en 225 pacientes con falla cardiaca con fracción de eyección reducida y déficit de hierro, en el cual no se encontró mejoría en el pico de oxígeno ni prueba de caminata de 6 min.

\section{Sistema respiratorio: enfermedad pulmonar obstructiva crónica}

La enfermedad pulmonar obstructiva crónica (EPOC) constituye la cuarta causa de muerte en todo el mundo; pero se estima que para el 2020 se va a convertir en la tercera causa de muerte. Es una enfermedad frecuente, prevenible, tratable y se caracteriza por síntomas respiratorios y limitación al flujo aéreo persistente, lo cual es secundario a alteraciones en las vías respiratorias y alvéolos tras la exposición de gases o partículas nocivas (36). En el estudio de Barberan et al. (37), en el cual se buscaba evaluar el impacto de la ferropenia sin anemia en pacientes EPOC en la capacidad aeróbica, definiendo ferropenia como una ferritina $<100 \mathrm{~g} / \mathrm{dL}$, se encontró una prevalencia del $48 \%$, lo cual es un valor alto $y$ que no tiene en cuenta aquellos pacientes con ferritina entre 100 y $300 \mathrm{~g} / \mathrm{dL}$ con transferrina $<$ $20 \%$, pues ello implicaría una mayor prevalencia.

Se cree que la ferropenia podría influir negativamente en el pronóstico del paciente a través de la alteración en la producción y función de las coenzimas que contienen hierro, lo cual implicaría una alteración en la función normal de los músculos respiratorios (38). En el estudio prospectivo publicado en el 2015 por Barberan et al. (37) se buscaba evaluar la relación entre la ferropenia sin anemia y la capacidad aeróbica en los pacientes con EPOC antes de un programa de alta intensidad y después de este. Se incluyeron 110 pacientes con EPOC, de los cuales 70 hicieron parte de la evaluación final, en la cual se constató una prevalencia del $48 \%$, una mayor tasa inicial de fumadores activos, disminución de la capacidad de difusión del dióxido de carbono y el tiempo de resistencia en el grupo de ferropenia en comparación con el grupo de hierro normal.

Adicionalmente, se evidenció una mejoría en la capacidad aeróbica solo en pacientes con hierro normal, lo cual indica una disminución en la respuesta al entrenamiento y terapia de rehabilitación en pacientes con ferropenia sin anemia (37). De forma contraria, en un estudio en el cual se tomaron datos clínicos de 107 pacientes con EPOC, solo un paciente $(0,9 \%)$ presentaba ferropenia sin anemia (39). En este último estudio, el segundo objetivo era evaluar el impacto en los parámetros hematológicos, así como en la percepción de la disnea tras la administración de eritropoyetina e hierro endovenoso (hierro sacarosa), y aunque el único paciente con ferropenia sin anemia no hizo parte de esta evaluación, cabe mencionar que en el grupo intervención hubo una mejoría en la hemoglobina y en la calidad de vida. Esto último nos hace cuestionarnos si la relación entre deficiencia de hierro y EPOC tendrá el mismo curso de la falla cardiaca, donde los estudios comenzaron de forma similar (39).

Se sabe que el hierro tiene una relación con el volumen espiratorio forzado en la fracción de eyección del ventrículo izquierdo, siendo menor este volumen en pacientes con hierro bajo (40). Se cree que el mecanismo fisiopatológico puede estar relacionado con la afectación muscular derivada del déficit de hierro; sin embargo, al igual que en la fisiopatología de la ferropenia en la EPOC, aún no están claros todos los mecanismos que llevan al compromiso de la funcionalidad del pulmón por déficit de hierro ni por qué se provoca este último. Dentro de las teorías planteadas hasta el momento, la que tiene más fuerza es la inflamación crónica, donde la hepcidina producida en los hepatocitos y macrófagos alveolares ejerce un papel importante (41). Se ha demostrado cómo por medio de la IL-6 y el interferón gamma se desencadena la producción de hepcidina desde los dos tipos de células anteriormente nombradas; de igual manera, el cigarrillo y la EPOC per se aumentan la permeabilidad capilar y permiten la distribución 
sistémica de los mediadores inflamatorios, lo cual estaría relacionado con el aumento de los niveles de hepcidina (figura 3).

\section{Figura 3}

Fisiopatología déficit de hierro en la EPOC: la hepcidina no solo inhibe la acción de la ferroportina en el intestino, como lo muestra la figura, sino que las células que se encuentran en el espacio alveolar y su alrededor también son afectadas por la acción de esta hormona.

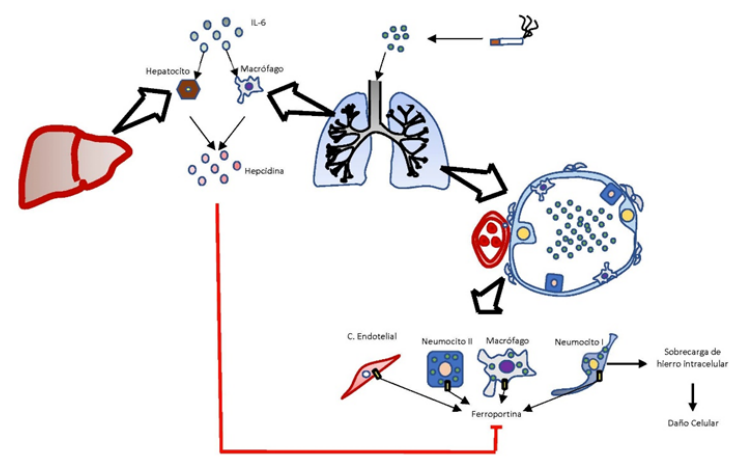

Fuente: imagen realizada por Daniel Martín et al., basada en González Alayón C, Pedrajas Crespo C, Marín Pedrosa S, Benítez JM, Iglesias Flores E, Salgueiro Rodríguez I, et al. Prevalencia de déficit de hierro sin anemia en la enfermedad inflamatoria intestinal y su impacto en la calidad de vida. Gastroenterol Hepatol. 2017 Sep;41(1):22-9.

\section{Sistema digestivo}

La anemia asociada con patología gastrointestinal ha sido ampliamente estudiada, considerándose la complicación extraintestinal más frecuente en patologías como la enfermedad inflamatoria intestinal $(42,43,44,45)$. En cuanto a la ferropenia sin anemia o deficiencia de hierro sin anemia y la afectación que esta produce a la calidad de vida de pacientes con patología gastrointestinal, es muy reducida. La prevalencia oscila entre 13 y $90 \%$ en enfermedad inflamatoria intestinal (42), un rango muy amplio, ya que los estudios suelen usar criterios para anemia, mas no para deficiencia de hierro sin anemia, y en la práctica clínica no suele investigarse esta última con parámetros de hemoglobina o hematocrito normales. Otros estudios muestran que la prevalencia de anemia está entre 36 y
$76 \%$, asociada a ferropenia en la mayoría de casos $(42,43)$.

Existen múltiples mecanismos fisiopatológicos que explican ferropenia y posterior anemia: sangrados crónicos, malabsorción e inflamación $(43,46)$. Los sangrados crónicos pueden ser provocados por úlceras o várices causadas por diferentes patologías en el tubo digestivo; así mismo, trastornos en la absorción, donde cobra mayor relevancia la infección por Helicobacter pylori, donde variables como el $\mathrm{pH}$ y el ácido ascórbico afectan la absorción de hierro. La infección por este microrganismo produce cambios histopatológicos inflamatorios en la mucosa gástrica y duodenal, inactivación del ácido ascórbico, que disminuyen su biodisponibilidad a través de receptores de membrana de lactoferrina. Adicionalmente, aumenta la concentración de hepcidina, lo cual disminuye la absorción del hierro $(47,48)$.

La enfermedad inflamatoria intestinal es parte de un grupo de patologías con etiología multifactorial, de componente autoinmune, donde existe una respuesta inflamatoria en la mucosa intestinal que la erosiona y la destruye. Los sangrados producidos por estas lesiones, los trastornos en la absorción dada la inflamación crónica, la alteración de la absorción por los procedimientos quirúrgicos que se evidencian con mayor frecuencia en la enfermedad de Crohn $(43,45,47)$ son los principales responsables de que sea mayor la prevalencia de la deficiencia de hierro sin anemia. En un estudio realizado con 111 pacientes con enfermedad de Crohn $(61,4 \%)$ o colitis ulcerativa $(38,6 \%)$ sin anemia se encontraron 47 (37\%) pacientes con alteraciones en la ferritina y la transferrina, siendo la presencia de actividad de la enfermedad la de mayor correlación $(\mathrm{OR}=9,4 ; 2,5-35,9 ;$ IC 95\%; $\mathrm{p}=$ 0,001).

\section{Sistema nervioso central}

\section{Proliferación y diferenciación neuronal}

El papel del hierro en el desarrollo cerebral ha sido un tema de interés durante los últimos 25 
años. Múltiples estudios han identificado cómo la deficiencia de hierro ha llevado a la formación de procesos patológicos y a la alteración de los procesos de desarrollo. Se han identificado diversas regiones afectadas como lo son el eje hipotálamo-pituitaria-adrenal, el estriado y el hipocampo. Así mismo, hay diferentes procesos bioquímicos afectados, como la fosforilación oxidativa, la producción dopaminérgica, el metabolismo de los ácidos grasos y la síntesis de nucleótidos.

Un estudio en modelos animales demostró que la deficiencia de hierro sin anemia tiene efectos en las neuronas hipocampales, por ejemplo, anormalidades moleculares, bioquímicas, estructurales y comportamentales. Las concentraciones de hierro regulan la formación de glutamato y su secreción. Esto es de particular importancia, pues los niveles de glutamato normales y el metabolismo energético son críticos para la morfogénesis de dendritas y la formación de sinapsis, particularmente en el hipocampo (49). El hipocampo es central para el procesamiento de la memoria de reconocimiento, particularmente el hipocampo doral, incluyendo áreas extensas de CA1 (cornu ammonis), que son importantes en los cambios estructurales y bioquímicos involucrados en la codificación de los eventos de memoria declarativa en humanos.

\section{Mielinización}

En cuanto a su rol en la mielinización, varios estudios lo han demostrado en la síntesis de lípidos de la mielina y fosfolípidos. También se postulan mecanismos adicionales como lo son cambios en los preoligodendrocitos tempranos y oligodendocritos, y alteraciones en la captación de hierro por los oligodendocritos por la transferrina (50). La deficiencia de hierro en etapas cruciales y la duración de esta deficiencia son factores clave para determinar las consecuencias cerebrales. La mielinización alterada puede llevar a daños en el desarrollo de los infantes (2). El periodo más alto de captación de hierro en el sistema nervioso central coincide con el pico de mielinización (50). El tiempo de aporte de hierro a los oligodendocritos durante el desarrollo es importante, pues la hipomielinización y las secuelas neurológicas subsecuentes persisten posterior a la corrección de la deficiencia (51).

\section{Arborización dendrítica}

La deficiencia de hierro temprana en neuronas, mediante la alteración de la función mitocondrial y el metabolismo energético de las neuronas, es responsable de defectos en la maduración sináptica y dendrítica de las neuronas. En modelos de cultivos celulares embrionarios de neuronas hipocampales expuestos a un agente quelante de hierro se evidenció que el número de dendritas era menor, al igual que su longitud, y así mismo había disminución de las ramificaciones secundarias y terciarias comparados con el control. Las neuronas con déficit de hierro permanecen anormales durante el periodo de desarrollo con campos dendríticos obtusos y expresión anormal de genes involucrados en el neurodesarrollo $(49,52)$.

\section{Sindrome de piernas inquietas}

El síndrome de piernas inquietas, también conocido como la enfermedad de Willis-Ekborn, es una enfermedad neurológica común. El 7,2\% de los adultos norteamericanos y europeos reporta haber experimentado los síntomas del síndrome de piernas inquietas en algún punto durante un periodo de un año, y el 5\% reporta experimentar los síntomas de forma semanal. Este síndrome se caracteriza por la aparición de urgencia irresistible de mover las piernas, acompañado de síntomas desagradables, la presentación o el empeoramiento de estos síntomas durante el sueño, el reposo o la inactividad, la mejoría total o parcial moviendo las piernas y el empeoramiento o su aparecimiento al atardecer o durante la noche $(53,54)$.

La deficiencia de hierro con anemia y sin esta se reconoce actualmente como un mecanismo fisiopatológico inicial en el desarrollo de esta 
entidad. La relación entre el nivel de hierro y el síndrome de piernas inquietas se examinó en 18 ancianos con esta enfermedad y 18 sujetos control. Calificaron en una escala con un puntaje máximo de 10 la severidad de la enfermedad y evaluaron los niveles de ferritina séricos. Se encontró que los niveles de ferritina estuvieron disminuidos en los pacientes con síndrome de piernas inquietas, comparados con los sujetos control, y como hallazgo relevante los niveles de hemoglobina no cambiaron entre los dos grupos (55). Los estudios más tempranos sobre síndrome de piernas inquietas revelaron que cerca del $25 \%$ de los pacientes tiene deficiencia de hierro (56). Modelos animales también han establecido la relación entre la deficiencia de hierro cerebral y la función dopaminérgica alterada en el síndrome de piernas inquietas, sobre todo con la disminución de la densidad de receptores D2 en el estriado y con aumento en la actividad de la tirosina hidroxilasa en el mesencéfalo $(57,58)$.

Adicionalmente, la síntesis de mielina depende del hierro, y la deficiencia del hierro en modelos animales reduce las proteínas, los lípidos y el colesterol de la mielina. La deficiencia de hierro cerebral en el síndrome de piernas inquietas es capaz de producir un déficit significativo de mielina, confirmado por estudios de imagen que demuestran una disminución significativa de la sustancia blanca en el cuerpo calloso, el cíngulo anterior y el giro precentral. La disminución de la mielinización contribuye a los síntomas de la enfermedad en relación con la integración sensorimotora que tiene una señalización tiempo dependiente (58).

Los niveles de ferritina en el líquido cefalorraquídeo son menores en los casos de síndrome de piernas inquietas, comparado con controles, y los estudios avanzados con resonancia magnética demuestran depósitos de hierro menores en el estriado, el tálamo y el núcleo rojo. Adicionalmente, la deficiencia de hierro en diferentes regiones cerebrales en el síndrome de piernas inquietas involucra una falla para proveer un transporte adecuado de hierro a través de la barrera hematoencefálica, llevando a una falla regional para importar hierro en neuronas críticas como lo son las células de neuromelanina en la sustancia nigra $(59,60)$.

Con base en este papel relevante de la deficiencia de hierro se han planteado diferentes estrategias terapéuticas. En el estudio previamente mencionado, 15 de los pacientes ancianos con síndrome de piernas inquietas se trataron con sulfato ferroso durante dos meses, y los puntajes de severidad del síndrome mejoraron en un valor medio de 4 puntos en 6 pacientes con ferritina menor o igual de $18 \mu \mathrm{g} / \mathrm{L}$, y en 3 puntos en 4 pacientes con ferritina mayor de 18 $\mu \mathrm{g} / \mathrm{L}$, menor o igual de $45 \mu \mathrm{g} / \mathrm{L}$, y en un punto en 5 pacientes con niveles de ferritina mayor de 45 $\mu \mathrm{g} / \mathrm{L}$ y menores de $100 \mu \mathrm{g} / \mathrm{L}$. Se concluyó que la deficiencia de hierro con anemia y sin esta es un factor importante en el desarrollo del síndrome de piernas inquietas y el suplemento de hierro puede generar una reducción significativa de los síntomas (55).

Las concentraciones de ferritina menores de 45-50 $\mu \mathrm{g} / \mathrm{L}$ se han asociado con una mayor severidad de los síntomas, y el suplemento de hierro se sugiere si los niveles de ferritina son menores de $75 \mu \mathrm{g} / \mathrm{L}$. Esta recomendación se basa en ensayos clínicos controlados que han mostrado el beneficio de la terapia. Un ensayo clínico aleatorizado con control con placebo, doble ciego, asignó pacientes a terapia con hierro oral vs. placebo durante 12 semanas. Luego de este periodo los puntajes de las escalas de valoración disminuyeron más en el brazo de tratamiento $(\mathrm{p}=0,01)$, y los niveles de ferritina incrementaron más en este grupo $(p=0,04)$.

Este fue el primer estudio en demostrar una mejoría estadísticamente significativa de los síntomas del síndrome de piernas inquietas usaron la terapia con hierro oral en pacientes con ferritina normal baja (61). En otro ensayo clínico controlado doble ciego aleatorizado con control con placebo, 11 pacientes fueron asignados al azar para la administración de hierro dextrano, y 14 pacientes a la administración de solución salina. Los puntajes de severidad del síndrome mejoraron significativamente junto con los síntomas en los participantes expuestos a la terapia con hierro dextrano, y sucedió a la semana luego de la infusión $(p=0,03)$ y fue 
máxima la mejoría a las 2 semanas $(\mathrm{p}=0,01)$ (62).

Finalmente, dos estudios evaluaron el papel de la carboximaltosa férrica. Uno fue un ensayo clínico controlado aleatorizado, multicéntrico, con control con placebo, en el que encontraron que esta mejoró significativamente la escala de severidad del síndrome de piernas inquietas de 8,9 puntos $(\mathrm{p}=0,040)$, la calidad de vida y demostraron que es un tratamiento efectivo y seguro, pues no hubo efectos adversos (63). El segundo estudio fue un ensayo clínico controlado doble ciego, aleatorizado, con control con placebo en el que se tomaron pacientes con síndrome idiopático no anémicos, y recibieron $1000 \mathrm{mg}$ del tratamiento o placebo en infusión única (64).

Estos sujetos estuvieron libres de medicamentos adicionales por, al menos, dos semanas antes de la evaluación de base. A la sexta semana posinfusión los pacientes con la terapia con carboximaltosa férrica demostraron una mejoría significativa en la escala de severidad de síndrome de piernas inquietas $(\mathrm{p}=0,03)$ y una escala visual análoga de severidad ( $p$ $=0,001)$. Doce de los 32 sujetos tratados con hierro permanecieron libres de posteriores manejos a las 30 semanas con mejoría de los síntomas. Es importante aclarar que un metanálisis incluyendo varios de estos estudios encontró heterogeneidad significativa en la formulación del hierro usado, las características de los pacientes y la medición de los resultados, y encontró evidencia insuficiente para concluir el beneficio del hierro para el tratamiento del síndrome de piernas inquietas. Se debe avanzar en nuevos estudios para continuar esclareciendo el papel terapéutico del suplemento de hierro (65).

\section{Trastornos cognitivos}

Desde el ensayo clínico controlado de Brunner et al. (66), en 1996, que estudió pacientes adolescentes femeninas de los Estados Unidos con deficiencia de hierro sin anemia y que mostró una mejoría del aprendizaje verbal y en memoria con suplemento oral de hierro, hay más evidencia de que no solo la deficiencia de hierro con anemia, sino también la deficiencia de hierro sin anemia, afecta la cognición. Un estudio observacional transversal que evaluó 428 pacientes en adolescencia temprana de China midió las concentraciones de hierro séricas y evaluó el desempeño neurocognitivo de los participantes, y encontró que los pacientes con deficiencia de hierro se asociaron con menor desempeño en tareas de flexibilidad mental y abstracción y su habilidad de procesamiento espacial (67). Adicionalmente, los pacientes que sufren de deficiencia de hierro perinatal y posnatal muestran problemas en el neurodesarrollo, que altera el aprendizaje y la memoria (68).

Falkingham et al. (69) encontraron en una revisión sistemática y metanálisis de 2010 que el suplemento de hierro mejoraba la atención y la concentración en adolescentes y mujeres con déficit de hierro con anemia y $\sin$ esta. Desde entonces varios estudios han investigado esta relación y mediante sus intervenciones han establecido el papel de la deficiencia de hierro sin anemia en el desarrollo de trastornos cognitivos. Un ensayo clínico controlado aleatorizado doble ciego con control con placebo realizó una intervención en niños en Sudáfrica con ferropenia y pobre estado de ácidos grados omega 3.

Luego de varios meses de suplemento con hierro oral encontraron una mejoría cognitiva en los niños con deficiencia de hierro. Cabe resaltar que el 20\% presentaba anemia. Otro ensayo clínico controlado, con control con placebo, aleatorizado, asignó mujeres de 18 a 35 años con diferentes estados de hierro a la suplementación con hierro o a placebo (70). Se realizaron pruebas cognitivas. Las mujeres con un estado de hierro normal presentaban mejor desempeño en las pruebas cognitivas de base. Las mujeres con deficiencia de hierro y anemia se presentaban con menor desempeño y las que presentaban deficiencia de hierro sin anemia tenían un desempeño intermedio con respecto a los grupos previos. Luego del tratamiento durante 16 semanas de hierro oral, 
la mejoría de la ferritina sérica se asoció a una mejoría de 5-7 veces en el desempeño cognitivo, particularmente en las mujeres con deficiencia de hierro sin anemia (71).

Además de los efectos en personas jóvenes, se ha postulado el papel de la deficiencia de hierro en enfermedades neurodegenerativas, pues como hemos revisado previamente el hierro participa en el desarrollo cerebral, la neurogénesis y las funciones cognitivas (72). La deficiencia de hierro durante la gestación y en la vida posnatal temprana ha demostrado alterar la expresión de genes en la totalidad del cerebro y en el hipocampo. Un estudio utilizando modelos murinos confirmó que la deficiencia temprana de hierro altera la expresión de genes cuya disregulación está implicada en la etiología de la enfermedad de Alzheimer, como lo son Fnl1, Cst3, Apbb1, Clu, App y Htatip (73). Estos datos que presentaron en el estudio sugería que la deficiencia de hierro y no la anemia, altera la expresión de estos genes durante periodos vulnerables del desarrollo hipocampal (73).

Finalmente, la deficiencia de hierro, cuyo papel es clave en el transporte de oxígeno y almacenamiento, puede llevar a hipoxia cerebral y a deterioro cognitivo. Un estudio observacional transversal que evaluó pacientes ancianos que ingresaban al servicio de geriatría examinó a 622 pacientes valorando su función cognitiva y su estado de hierro. Encontraron una influencia negativa de la deficiencia de hierro sobre la función cognitiva y esta influencia fue independiente de la presencia de anemia. Los pacientes con deficiencia de hierro tenían menor puntaje en el Mini Mental State Examination ( $p$ $<0,001)$ y esta relación estaba presente en los pacientes sin anemia $(\mathrm{p}=0,004)(74)$.

\section{Sistema genitourinario}

\section{Enfermedad renal crónica}

El déficit de hierro en enfermedad renal crónica (ERC) es de alta prevalencia (57,8-72,8\%), un gran porcentaje de estos pacientes cursan con anemia asociada y toda la morbimortalidad que esto implica $(75,76,77)$. Esto ha llevado que alrededor del $85-90 \%$ requieran tratamiento con agentes estimulantes de la eritropoyesis. Sin embargo, el uso de estos agentes no compensa a todos los pacientes y alteraciones en el metabolismo del hierro serían los responsables de la presencia de resistencia (78). Hay múltiples estudios que evidencian que es tan primordial tratar la deficiencia de hierro con suplencia de este como el uso de inductores de la eritropoyesis, que producen mejoría en morbimortalidad calidad de vida y pronóstico del paciente.

La ERC produce disbalance en el metabolismo y absorción del hierro, la inflamación crónica lleva a la producción de citocinas y otros productos de la inflamación, en especial la IL-6 aumenta la producción de hepcidina a nivel hepático, disminuyendo así la absorción de hierro digestiva por inhibición de canales ferroportina 1; además, aumenta la captación de hierro por los macrófagos, pero disminuyen su liberación en estas células y en el sistema hepático produciendo así una deficiencia de hierro $(79,80,81,82)$. Se postula, además, que la uremia, característica de estos pacientes, inhibe factores hematopoyéticos y altera el metabolismo del hierro. También vemos que los pacientes con ERC tienen pérdidas directas de hierro asociado con hemorragias crónicas por disfunción plaquetaria producida por la uremia (79), flebotomías frecuentes y el atrapamiento de sangre en los circuitos de diálisis. Todo esto nos lleva a un déficit de hierro real; por otro lado, existe un déficit de hierro funcional o bloqueo de hierro en células reticuloendoteliales, asociado al uso de agentes estimulantes de la eritropoyesis $(78,79,83)$.

El diagnóstico de déficit de hierro en ERC sin diálisis está basado en niveles de ferritina $<100 \mathrm{ng} / \mathrm{dL}$ y $<200 \mathrm{ng} / \mathrm{dL}$ en pacientes sometidos a diálisis, además de un índice de saturación de transferrina $<20 \%$ (84). Las guías diagnósticas recomiendan determinar un porcentaje de glóbulos rojos hipocrómicos (< $6 \%)$ y hemoglobina en reticulocitos $(<29 \mathrm{pg})$, ya que estos son parámetros más sensibles para determinar déficit de hierro funcional y no se alteran ante el uso de estimulantes de la eritropoyesis, además de ser mejores predictores 
de una adecuada respuesta al tratamiento a la suplementación de hierro $(5,83,85,86)$.

Cuando encontramos niveles de ferritina bajos asociados con transferrina baja, estamos ante un déficit de hierro real; por otro lado, si hallamos niveles de ferritina altos con una transferrina baja, asociados con un aumento en el porcentaje de glóbulos rojos hipocrómicos y niveles bajos de hemoglobina en reticulocitos, hay reservas de hierro adecuadas pero inefectivas, es decir, un déficit de hierro funcional. Es importante determinar la diferencia entre estos dos tipos de déficit de hierro, ya que son mecanismos fisiopatológicos diferentes, y en el caso del déficit de hierro funcional, aumenta el estrés oxidativo y el riesgo de infección. Además, si no se diagnostica, suele aumentarse la dosis de agentes estimulantes de la eritropoyesis, sin adecuados objetivos terapéuticos, que aumentan la incidencia de reacciones adversas como hipertensión arterial, coágulos en las vías de diálisis, entre otras. A este fenómeno se le denomina hiporreactividad o resistencia a los estimulantes de eritropoyesis, definida como dos niveles consecutivos de hemoglobina $<10 \mathrm{~g} / \mathrm{dL}$ mientras recibía eritropoyetina $>7700$ unidades por dosis, que puede ocurrir en un 10-20\% de los pacientes $(79,83)$.

Es necesario dividir a los pacientes con ERC en quienes son sometidos o no a diálisis. Los pacientes sin diálisis candidatos a tratamiento con suplemento de hierro son aquellos con transferrina $<20 \%$ o ferritina $<100 \mathrm{ng} /$ dL (recuérdese la definición de déficit de hierro funcional) o mayores a esto si presenta hemoglobina $<13$ en hombres o mujeres posmenopáusicas o $<12$ en mujeres en edad fértil $(83,87)$. Varios estudios han señalado que el citrato ferroso estabiliza los parámetros mencionados de manera más eficaz $(87,88,89)$. Se podrán utilizar agentes intravenosos cuando hay un déficit de hierro severo (transferrina $<$ $12 \%$ ), riesgo de sangrado elevado (pacientes con comorbilidades gastrointestinales) y antecedente de no mejoría con el uso de hierro vía oral.

En este grupo de pacientes, el más utilizado es el gluconato férrico, en dosis de $250 \mathrm{mg}$, semanal, de 3 a 4 dosis. Otras opciones son el ferumoxutol, hierro sacarosa y carboximaltosa de hierro que muestran igual eficacia, pero con diferencia en costos. No se recomienda hierro dextrano, por la mayor incidencia de reacciones anafilácticas. El tratamiento oral, en comparación con el tratamiento intravenoso, es un tema de debate en este grupo de pacientes; algunos estudios muestran las ventajas de la terapia intravenosa respecto a la mejoría en los índices de homeostasia del hierro, además de disminuir las dosis de estimulantes de la eritropoyesis. Por lo tanto, hay evidencia de que esta es la vía de administración óptima $(87,88,89,90,91,92)$; las guías recomiendan en este grupo de pacientes el uso de hierro oral, por temas prácticos, en aquellos que no usan agentes estimulantes de la eritropoyesis, o la usan en bajas dosis y ofrecen terapia intravenosa en aquellos que no toleran la vía oral o que no muestren mejoría en los primeros tres meses de tratamiento con hierro oral.

\section{Conclusiones}

Durante muchos años se ha enfocado la atención en la hemoglobina como el parámetro más importante en el diagnóstico de la anemia; no obstante, como podemos observar en el presente artículo, este hallazgo es tardío y existe un gran número de cambios que preceden la disminución de esta proteína en la sangre. En el caso de la anemia por déficit de hierro, son múltiples las ayudas diagnósticas que muestran las alteraciones en el metabolismo del hierro y que representan los distintos estadios de la disminución de los depósitos de hierro, que en su gran mayoría se presentan antes de la reducción en los valores de hemoglobina. La ferropenia sin anemia es el término que se acuñó a la alteración de estos parámetros sin aún tener descenso de hemoglobina.

Inicialmente, no se buscaba ni se conocía la importancia de este diagnóstico; sin embargo, con el avance en los métodos diagnósticos podemos darnos cuenta de que la presencia de este hallazgo se relaciona con cambios funcionales cardiacos, deterioro de la calidad 
de vida por disnea, alteraciones cognitivas, entre otras. En falla cardiaca y en insuficiencia renal se conoce mucho sobre el impacto de la ferropenia; pero aún existen brechas importantes en la fisiopatología, diagnóstico temprano y las implicaciones de su reposición en las distintas enfermedades.

\section{Referencias}

1. Sohrabi F. Tip of the iceberg: Extra-haematological consequences of early iron deficiency. J Glob Health [Internet]. 2015;5(2):20304. Disponible en: http://www.ncbi.nlm.nih.gov/ pubmed/26421147\%0A http:// www.pubmedcentral.nih.gov/ articlerender.fcgi? artid=PMC4587592\%0A http:// www.jogh.org/pdfviewer.html? $\mathrm{pdf}=$ documents/forthcoming/ jogh-05-020304.pdf

2. Baart AM, van Noord PAH, Vergouwe Y, Moons KGM, Swinkels DW, Wiegerinck ET, et al. High prevalence of subclinical iron deficiency in whole blood donors not deferred for low hemoglobin. Transfusion [Internet]. 2013 Aug 1 [citado 2017 Oct 28];53(8):1670-7. Disponible en: http://doi.wiley.com/10,1111/ j.1537-2995,2012,03956.x

3. Brittenham GM. Disorders of iron homeostasis: Iron deficiency and overload. En Hematology: Basic Principles and Practice. 7th ed. Philadelphia: Elsevier; 2013. p. 437-49.

4. Bentley DP, Williams P. Serum ferritin concentration as an index of storage iron in rheumatoid arthritis. J Clin Pathol [Internet]. 1974 Oct [citado 2017 Oct 25];27(10):786-8. Disponible en: http://www.ncbi.nlm.ni h.gov/pubmed/4426972
5. Tessitore N, Solero GP, Lippi G, Bassi A, Faccini GB, Bedogna V, et al. The role of iron status markers in predicting response to intravenous iron in haemodialysis patients on maintenance erythropoietin. Nephrol Dial Transplant [Internet]. $2001 \mathrm{Jul}$ [citado 2017 Oct 25];16(7):1416-23. Disponible en: http://www.ncbi.nlm.ni h.gov/pubmed/11427634

6. Clénin GE. The treatment of iron deficiency without anaemia (in otherwise healthy persons). Swiss Med Wkly [Internet]. 2017 Jun 14 [citado 2017 Oct 25];147(2324):w14434. Disponible en: http://www.ncbi.nlm.ni h.gov/pubmed/28634965

7. Wang W, Knovich MA, Coffman LG, Torti FM, Torti S V. Serum ferritin: Past, present and future. [citado 2017 Oct 25]. Disponible en: https://www.ncbi.nlm.nih.gov/pmc /articles/PMC2893236/pdf/nihms1909 12.pdf

8. Lopez A, Cacoub P, Macdougall IC, Peyrin-Biroulet L. Iron deficiency anaemia. Lancet. 2016;387 (10021):907-16.

9. Mast AE, Blinder MA, Lu Q, Flax S, Dietzen DJ. Clinical utility of the reticulocyte hemoglobin content in the diagnosis of iron deficiency. Blood [Internet]. 2002 Feb 15 [citado 2017 Oct 28];99(4):1489-91. Disponible en: http://www.ncbi.nlm.nih.gov/pubm ed/11830506

10. Urrechaga E, Borque L, Escanero JF. Clinical value of hypochromia markers in the detection of latent iron deficiency in nonanemic premenopausal women. J Clin Lab Anal [Internet]. 2016 Sep [citado 2017 Oct 28];30(5):623-7. Disponible en: http://www.ncbi.nlm.nih.gov/pubm ed/26899023

11. Malczewska-Lenczowska J, Orysiak J, Szczepańska B, Turowski D, 
Burkhard-Jagodzińska K, Gajewski J. Reticulocyte and erythrocyte hypochromia markers in detection of iron deficiency in adolescent female athletes. Biol Sport. 2017;34(2):111-8.

12. Witte KKA, Desilva R, Chattopadhyay S, Ghosh J, Cleland JGF, Clark AL. Are hematinic deficiencies the cause of anemia in chronic heart failure? Am Heart J. 2004;147(5):924-30.

13. van Veldhuisen DJ, Anker SD, Ponikowski P, Macdougall IC. Anemia and iron deficiency in heart failure: Mechanisms and therapeutic approaches. Nat Rev Cardiol [Internet]. 2011;8(9):485-93. Disponible en: http://www.nature.com/ doifinder/10,1038/nrcardio.2011,77

14. de Silva R, Rigby AS, Witte KKA, Nikitin NP, Tin L, Goode $\mathrm{K}$, et al. Anemia, renal dysfunction, and their interaction in patients with chronic heart failure. Am J Cardiol [Internet]. 2006 Aug 1 [citado 2017 Oct 30];98(3):391-8. Disponible en: http://www.ncbi.nlm.nih.gov/pubm ed/16860030

15. Jankowska EA, Rozentryt P, Witkowska A, Nowak J, Hartmann $\mathrm{O}$, Ponikowska $\mathrm{B}$, et al. Iron deficiency: An ominous sign in patients with systolic chronic heart failure. Eur Heart J [Internet]. 2010 Aug 1 [citado 2017 Oct 30];31(15):1872-80. Disponible en: https://academic.oup.com/eurheartj/ article-lookup/doi/10,1093/eurheartj/ ehq158

16. Grammer TB, Kleber ME, Silbernagel G, Pilz S, Scharnagl H, Tomaschitz A, et al. Hemoglobin, iron metabolism and angiographic coronary artery disease (The Ludwigshafen Risk and Cardiovascular Health Study). Atherosclerosis [Internet]. 2014 Oct [citado 2017 Oct 30];236(2):292-300.
Disponible en: http://www.ncbi.nlm.ni h.gov/pubmed/25112800

17. Meroño O, Cladellas M, RibasBarquet N, Recasens L, Bazán V, Comín-Colet J. Iron deficiency in patients with acute coronary syndrome: Prevalence and predisposing factors. Rev Española Cardiol (English Ed [Internet]. 2016 Jun 1 [citado 2017 Oct 30];69(6):615-7. Disponible en: http://linkinghub.elsevier.com/retri eve/pii/S188558571630010X

18. Huang C-H, Chang C-C, Kuo C-L, Huang C-S, Chiu T-W, Lin C$\mathrm{S}$, et al. Serum iron concentration, but not hemoglobin, correlates with TIMI risk score and 6-month left ventricular performance after primary angioplasty for acute myocardial infarction. En Guo Y, editor. PLoS One [Internet]. 2014 Aug 6 [citado 2017 Oct 30];9(8):e104495. Disponible en: http://dx.plos.org/10,1371/ journal.pone.0104495

19. Jankowska EA, Wojtas K, Kasztura M, Mazur G, Butrym A, Kalicinska E, et al. Bone marrow iron depletion is common in patients with coronary artery disease. Int J Cardiol [Internet]. 2015 Mar 1 [citado 2017 Oct 30];182:517-22. Disponible en: http://www.ncbi.nlm.nih.gov/pubm ed/25661858

20. Rangel I, Gonçalves A, De Sousa C, Leite S, Campelo M, Martins $\mathrm{E}$, et al. Iron Deficiency status irrespective of anemia: A predictor of unfavorable outcome in chronic heart failure patients. Cardiology [Internet]. 2014 [citado 2017 Oct 31];128:320-6. Disponible en: https://www.karger.com /Article/Pdf/358377

21. Anand I. Iron deficiency in heart failure. Cardiol [Internet]. 2014;128(4):317-9. Disponible en: http://ovidsp.ovid.com 
22. Nanas JN, Matsouka C, Karageorgopoulos D, Leonti A, Tsolakis E, Drakos SG, et al. Etiology of anemia in patients with advanced heart failure. J Am Coll Cardiol [Internet]. 2006 Dec [citado 2017 Oct 31];48(12):2485-9. Disponible en: http://linkinghub.elsevier.com/retri eve/pii/S0735109706023485

23. Weiss G, Goodnough LT. Anemia of Chronic Disease. N Engl J Med [Internet]. 2005 Mar 10 [citado 2017 Oct 31];352(10):1011-23. Disponible en: http://www.nejm.org/ doi/abs/10,1056/NEJMra041809

24. Naito Y, Tsujino T, Fujimori Y, Sawada H, Akahori H, Hirotani $\mathrm{S}$, et al. Impaired expression of duodenal iron transporters in Dahl salt-sensitive heart failure rats. J Hypertens [Internet]. 2011 Apr 1 [citado 2017 Oct 31];29(4):741-8. Disponible en: https://insights.ovid.co $\mathrm{m} /$ pubmed? pmid $=21191310$

25. Silverberg DS, Wexler D, Blum M, Keren G, Sheps D, Leibovitch $\mathrm{E}$, et al. The use of subcutaneous erythropoietin and intravenous iron for the treatment of the anemia of severe, resistant congestive heart failure improves cardiac and renal function and functional cardiac class, and markedly reduces hospitalizations. J Am Coll Cardiol [Internet]. 2000 [citado 2017 Nov 1];35:1737-44.

26. Silverberg DS, Wexler D, Sheps D, Blum M, Keren G, Baruch R, et al. The effect of correction of mild anemia in severe, resistant congestive heart failure using subcutaneous erythropoietin and intravenous iron: a randomized controlled study. J Am Coll Cardiol [Internet]. 2001 Jun 1 [citado 2017 Nov 1];37(7):1775-80. Disponible en: http://www.ncbi.nlm.ni h.gov/pubmed/11401110
27. Palazzuoli A, Silverberg D, Iovine F, Capobianco S, Giannotti G, Calabrò A, et al. Erythropoietin improves anemia exercise tolerance and renal function and reduces B-type natriuretic peptide and hospitalization in patients with heart failure and anemia. Am Heart J [Internet]. 2006 Dec [citado 2017 Nov 1];152(6):1096.e9-1096.e15. Disponible en: http://www.ncbi.nlm.ni h.gov/pubmed/17161060

28. Mancini DM, Katz SD, Lang CC, LaManca J, Hudaihed A, Androne AS. Effect of erythropoietin on exercise capacity in patients with moderate to severe chronic heart failure. Circulation [Internet]. 2003 Jan 21 [citado 2017 Nov 1];107(2):294-9. Disponible en: http://www.ncbi.nlm.ni h.gov/pubmed/12538431

29. Ponikowski P, Anker SD, Szachniewicz J, Okonko D, Ledwidge $\mathrm{M}$, Zymlinski R, et al. Effect of darbepoetin alfa on exercise tolerance in anemic patients with symptomatic chronic heart failure. J Am Coll Cardiol [Internet]. 2007 Feb 20 [citado 2017 Nov 1];49(7):753-62. Disponible en: http://www.ncbi.nlm.nih.gov/pubm ed/17306703

30. Ghali JK, Anand IS, Abraham WT, Fonarow GC, Greenberg B, Krum H, et al. Randomized double-blind trial of darbepoetin alfa in patients with symptomatic heart failure and anemia. Circulation [Internet]. 2008 Jan 29 [citado 2017 Nov 1];117(4):526-35 Disponible en: http://www.ncbi.nlm.ni h.gov/pubmed/18195176

31. van Veldhuisen DJ, Dickstein K, Cohen-Solal A, Lok DJA, Wasserman SM, Baker N, et al. Randomized, double-blind, placebo-controlled study to evaluate the effect of two dosing regimens of darbepoetin alfa in patients with heart failure and anaemia. Eur Heart J [Internet]. 2007 Aug 2 
[citado 2017 Nov 1];28(18):2208-16. Disponible en: http://www.ncbi.nlm.ni h.gov/pubmed/17681958

32. Bolger AP, Bartlett FR, Penston hierro sérico, O'Leary J, Pollock N, Kaprielian R, et al. Intravenous iron alone for the treatment of anemia in patients with chronic heart failure. J Am Coll Cardiol [Internet]. 2006 Sep 19 [citado 2017 Nov 1];48(6):1225-7. Disponible en: http://www.ncbi.nlm.ni h.gov/pubmed/16979010

33. Okonko D, Grzeslo A, Witkowski T, Mandal A, Slater R, Roughton $M$, et al. Effect of intravenous iron sucrose on exercise tolerance in anemic and nonanemic patients with symptomatic chronic heart failure and iron deficiency: FERRIC-HF: A randomized, controlled, observerblinded trial. J Am Coll Cardiol [Internet]. 2008 Jan 15 [citado 2017 Nov 1];51(2):103-12. Disponible en: http://www.sciencedirect.com/scie nce/article/pii/S0735109707033633

34. van Veldhuisen DJ, Ponikowski $\mathrm{P}$, van der Meer P, Metra M, Böhm M, Doletsky A, et al. Effect of Ferric carboxymaltose on exercise capacity in patients with chronic heart failure and iron deficiency. Circulation [Internet]. 2017 Oct 10 [citado 2017 Nov 2];136(15):1374-83. Disponible en: http://www.ncbi.nlm.nih.gov/pubm ed/28701470

35. Lewis GD, Malhotra R, Hernandez AF, McNulty SE, Smith A, Felker GM, et al. Effect of Oral iron repletion on exercise capacity in patients with heart failure with reduced ejection fraction and iron deficiency. JAMA [Internet]. 2017 May 16 [citado 2017 Nov 2];317(19):1958. Disponible en: http://jama.jamanetwork.com/ article.aspx?doi $=10,1001 /$ jama.2017,5427
36. Vogelmeier CF, Criner GJ, Martinez FJ, Anzueto A, Barnes PJ, Bourbeau J, et al. Global Strategy for the diagnosis, management, and prevention of chronic obstructive lung disease 2017 report. Gold executive summary. Am J Respir Crit Care Med [Internet]. 2017 Mar 1 [citado 2017 Nov 4];195(5):557-82. Disponible en: http://www.ncbi.nlm.ni h.gov/pubmed/28128970

37. Barberan-García A, Rodríguez DA, Blanco I, Gea J, Torralba Y, ArbillagaEtxarri A, et al. Non-anaemic iron deficiency impairs response to pulmonary rehabilitation in COPD. Respirology. 2015;20(7):1089-95.

38. Robalo Nunes A, Tátá M. The impact of anaemia and iron deficiency in chronic obstructive pulmonary disease: A clinical overview. Rev Port Pneumol (English Ed [Internet]. 2017 May [citado 2017 Nov 2];23(3):146-55. Disponible en: http://www.ncbi.nlm.nih.gov/pubm $\mathrm{ed} / 28233650$

39. Silverberg DS, Mor R, Weu MT, Schwartz D, Schwartz IF, Chernin G. Anemia and iron deficiency in COPD patients: Prevalence and the effects of correction of the anemia with erythropoiesis stimulating agents and intravenous iron. BMC Pulm Med [Internet]. 2014 Dec 24 [citado 2017 Nov 2];14(1):24. Disponible en: http://www.ncbi.nlm.nih.gov/pubm ed/24564844

40. McKeever TM, Lewis SA, Smit HA, Burney P, Cassano PA, Britton J. A multivariate analysis of serum nutrient levels and lung function. Respir Res [Internet]. 2008 Dec 29 [citado 2017 Nov 5];9(1):67. Disponible en: http://www.ncbi.nlm.ni h.gov/pubmed/18823528

41. Nguyen N-B, Callaghan KD, Ghio AJ, Haile DJ, Yang F. 
Hepcidin expression and iron transport in alveolar macrophages. Am J Physiol Lung Cell Mol Physiol [Internet]. 2006 Sep 1 [citado 2017 Nov 6];291(3):L417-25. Disponible en: http://www.ncbi.nlm.nih.gov/pubm ed/16648237

42. González Alayón C, Pedrajas Crespo C, Marín Pedrosa S, Benítez JM, Iglesias Flores E, Salgueiro Rodríguez I, et al. Prevalencia de déficit de hierro sin anemia en la enfermedad inflamatoria intestinal y su impacto en la calidad de vida. Gastroenterol Hepatol [Internet]. 2017 Sep [citado 2017 Nov 7]; Disponible en: http://linkinghub.elsevier.com/retri eve/pii/S0210570517301899

43. Bou-Fakhredin R, Halawi R, Roumi $\mathrm{J}$, Taher A. Insights into the diagnosis and management of iron deficiency in inflammatory bowel disease. Expert Rev Hematol [Internet]. 2017;10(9):801-8. Disponible en: https://www.tandfonline.com/doi/ full/10.1080/17474086.2017.1355233

44. Goddard AF, James MW, McIntyre AS, Scott BB, British Society of gastroenterology. guidelines for the management of iron deficiency anaemia. Gut [Internet]. 2011 Oct 1 [citado 2017 Nov 7];60(10):1309-16. Disponible en: http:/www.ncbi.nlm.ni h.gov/pubmed/21561874

45. Wilson A, Reyes E, Ofman J. Prevalence and outcomes of anemia in inflammatory bowel disease: a systematic review of the literature. Am J Med [Internet]. 2004 Apr 5 [citado 2017 Nov 7];116(7):44-9. Disponible en: http://www.ncbi.nlm.nih.gov/pubm ed/15050885

46. Stein J, Connor S, Virgin G, Ong DEH, Pereyra L. Anemia and iron deficiency in gastrointestinal and liver conditions. World J Gastroenterol [Internet]. 2016 Sep 21 [citado 2017
Nov 7];22(35):7908-25. Disponible en: http://www.ncbi.nlm.nih.gov/pubm ed/27672287

47. Stein J, Connor S, Virgin G, Ong DEH, Pereyra L. Anemia and iron deficiency in gastrointestinal and liver conditions. World J Gastroenterol. 2016;22(35):7908-25.

48. García Herce JA, Muñoz Gómez M. Hepcidina: una molécula clave para explicar la fisiopatología de la anemia. Gastroenterol y Hepatol Contin [Internet]. 2008 Jun [citado 2017 Nov 7];7(3):119-23. Disponible en: http://linkinghub.elsevier.com/retri eve/pii/S1578155008730018

49. Carlson ES, Tkac I, Magid $\mathrm{R}$, O'Connor $\mathrm{MB}$, Andrews $\mathrm{NC}$, Schallert $\mathrm{T}$, et al. Iron is essential for neuron development and memory function in mouse hippocampus. J Nutr [Internet]. 2009 Apr [citado 2017 Nov 7];139(4):672-9. Disponible en: http://www.ncbi.nlm.nih.gov/pubm ed/19211831

50. Lozoff B, Georgieff MK. Iron deficiency and brain development. Semin Pediatr Neurol [Internet]. 2006 Sep [citado 2017 Nov 7];13(3):158-65. Disponible en: http://www.ncbi.nlm.ni h.gov/pubmed/17101454

51. Todorich B, Pasquini JM, García CI, Páez PM, Connor JR. Oligodendrocytes and myelination: The role of iron. Glia [Internet]. 2009 Apr 1 [citado 2017 Nov 7];57(5):467-78. Disponible en: http://www.ncbi.nlm.nih.gov/pubm ed/18837051

52. Bastian TW, von Hohenberg WC, Mickelson DJ, Lanier LM, Georgieff MK. Iron deficiency impairs developing hippocampal neuron gene expression, energy metabolism, and dendrite complexity. Dev Neurosci [Internet]. $2016 \quad$ [citado 2017 Nov 7];38(4):264-76. Disponible 
en: http://www.ncbi.nlm.nih.gov/pubm ed/27669335

53. Benes H, Walters AS, Allen RP, Hening WA, Kohnen R. Definition of restless legs syndrome, how to diagnose it, and how to differentiate it from RLS mimics. Mov Disord [Internet]. 2007 Jan 1 [citado 2017 Nov 7];22(S18):S401-8. Disponible en: http://doi.wiley.com/10,1002/ mds.21604

54. Llaneza-González MA, AbellaCorral J, Aldrey-Vázquez JM, AneirosDíaz A, Macías-Arribi M, SantosGarcía D. Restless legs syndrome. Rev Neurol [Internet]. 2009 Jan 23 [citado 2017 Nov 7];48 Suppl 1:S33-6. Disponible en: http://www.ncbi.nlm.ni h.gov/pubmed/19222013

55. O'Keeffe ST, Gavin K, Lavan $\mathrm{JN}$. Iron status and restless legs syndrome in the elderly. Age Ageing [Internet]. 1994 May [citado 2017 Nov 7];23(3):200-3. Disponible en: http://www.ncbi.nlm.nih.gov/pubm ed/8085504

56. Zobeiri M, Shokoohi A. Restless leg syndrome in diabetics compared with normal controls. Sleep Disord [Internet]. 2014 [citado 2017 Nov 7];2014:871751. Disponible en: http://www.ncbi.nlm.nih.gov/pubm ed/24895540

57. Rizzo G, Manners D, Testa C, Tonon C, Vetrugno R, Marconi $\mathrm{S}$, et al. Low brain iron content in idiopathic restless legs syndrome patients detected by phase imaging. Mov Disord [Internet]. 2013 Nov [citado 2017 Nov 7];28(13):1886-90. Disponible en: http://www.ncbi.nlm.ni h.gov/pubmed/23780623

58. Connor JR, Wang X-S, Allen RP, Beard JL, Wiesinger JA, Felt $\mathrm{BT}$, et al. Altered dopaminergic profile in the putamen and substantia nigra in restless leg syndrome. Brain
[Internet]. 2009 Sep 1 [citado 2017 Nov 7];132(9):2403-12. Disponible en: http://www.ncbi.nlm.nih.gov/pubm ed/19467991

59. Earley CJ, Connor JR, Beard JL, Malecki EA, Epstein DK, Allen RP. Abnormalities in CSF concentrations of ferritin and transferrin in restless legs syndrome. Neurology [Internet]. 2000 Apr 25 [citado 2017 Nov 7];54(8):1698-700. Disponible en: http://www.ncbi.nlm.nih.gov/pubm ed/10762522

60. Connor JR, Ponnuru P, Lee BY, Podskalny GD, Alam S, Allen $\mathrm{RP}$, et al. Postmortem and imaging based analyses reveal CNS decreased myelination in restless legs syndrome. Sleep Med [Internet]. 2011 Jun [citado 2017 Nov 7];12(6):614-9. Disponible en: http://www.ncbi.nlm.nih.gov/pubm ed/21570342

61. Wang J, O'Reilly B, Venkataraman R, Mysliwiec V, Mysliwiec A. Efficacy of oral iron in patients with restless legs syndrome and a lownormal ferritin: A randomized, doubleblind, placebo-controlled study. Sleep Med [Internet]. 2009 Oct [citado 2017 Nov 7];10(9):973-5. Disponible en: http://www.ncbi.nlm.nih.gov/pubm ed/19230757

62. Sloand JA, Shelly MA, Feigin A, Bernstein P, Monk RD. A double-blind, placebo-controlled trial of intravenous iron dextran therapy in patients with ESRD and restless legs syndrome. Am J Kidney Dis [Internet]. 2004 Apr [citado 2017 Nov 7];43(4):663-70. Disponible en: http://www.ncbi.nlm.ni h.gov/pubmed/15042543

63. Allen RP, Adler $\mathrm{CH}, \mathrm{Du} \mathrm{W}$, Butcher A, Bregman DB, Earley CJ. Clinical efficacy and safety of IV ferric carboxymaltose (FCM) treatment of RLS: A multi-centred, placebo-controlled preliminary clinical 
trial. Sleep Med [Internet]. 2011 Oct [citado 2017 Nov 7];12(9):906-13. Disponible en: http://www.ncbi.nlm.ni h.gov/pubmed/21978726

64. Cho YW, Allen RP, Earley CJ. Clinical efficacy of ferric carboxymaltose treatment in patients with restless legs syndrome. Sleep Med [Internet]. $2016 \mathrm{Sep}$ [citado $2017 \mathrm{Nov}$ 7];25:16-23. Disponible en: http://ww w.ncbi.nlm.nih.gov/pubmed/27823710

65. Trotti LM, Bhadriraju S, Becker LA. Iron for restless legs syndrome. En: Trotti LM, editor. Cochrane database of systematic reviews [Internet]. Chichester, UK: John Wiley \& Sons; 2012 [citado 2017 Nov 7]. p. CD007834. Disponible en: http://www .ncbi.nlm.nih.gov/pubmed/22592724

66. Bruner AB, Joffe A, Duggan AK, Casella JF, Brandt J. Randomised study of cognitive effects of iron supplementation in non-anaemic irondeficient adolescent girls. Lancet [Internet]. 1996 Oct 12 [citado 2017 Nov 7];348(9033):992-6. Disponible en: http://www.ncbi.nlm.nih.gov/pubm ed/8855856

67. Ji X, Cui N, Liu J. Neurocognitive function is associated with serum iron status in early adolescents. Biol Res Nurs [Internet]. 2017 May 15 [citado 2017 Nov 7];19(3):269-77. Disponible en: http://www.ncbi.nlm.nih.gov/pubm ed/28196427

68. Radlowski EC, Johnson RW. Perinatal iron deficiency and neurocognitive development. Front Hum Neurosci [Internet]. 2013 Sep 23 [citado 2017 Nov 7];7:585. Disponible en: http://www.ncbi.nlm.nih.gov/pubm $\mathrm{ed} / 24065908$

69. Falkingham M, Abdelhamid A, Curtis P, Fairweather-Tait S, Dye L, Hooper L. The effects of oral iron supplementation on cognition in older children and adults: A systematic review and meta-analysis. Nutr J [Internet]. 2010 Jan 25 [citado 2017 Nov 7];9:4. Disponible en: http://www .ncbi.nlm.nih.gov/pubmed/20100340

70. Baumgartner J, Smuts CM, Malan L, Kvalsvig J, van Stuijvenberg ME, Hurrell RF, et al. Effects of iron and n-3 fatty acid supplementation, alone and in combination, on cognition in school children: a randomized, doubleblind, placebo-controlled intervention in South Africa. Am J Clin Nutr [Internet]. 2012 Dec 1 [citado 2017 Nov 7];96(6):1327-38. Disponible en: http://www.ncbi.nlm.nih.gov/pubm ed/23097272

71. Murray-Kolb LE, Beard JL. Iron treatment normalizes cognitive functioning in young women. Am J Clin Nutr [Internet]. 2007 Mar [citado 2017 Nov 7];85(3):778-87. Disponible en: http://www.ncbi.nlm.nih.gov/pubm ed/17344500

72. Belaidi AA, Bush AI. Iron neurochemistry in Alzheimer's disease and Parkinson's disease: Targets for therapeutics. J Neurochem [Internet]. 2016 Oct [citado 2017 Nov 7];139:179-97. Disponible en: http://www.ncbi.nlm.nih.gov/pubm ed/26545340

73. Carlson ES, Magid R, Petryk A, Georgieff MK. Iron deficiency alters expression of genes implicated in Alzheimer disease pathogenesis. Brain Res [Internet]. 2008 Oct 27 [citado 2017 Nov 7];1237:75-83. Disponible en: http://www.ncbi.nlm.nih.gov/ pubmed/18723004

74. Yavuz BB, Cankurtaran $M$, Haznedaroglu IC, Halil M, Ulger $\mathrm{Z}$, Altun $\mathrm{B}$, et al. Iron deficiency can cause cognitive impairment in geriatric patients. J Nutr Health Aging [Internet]. 2012 Mar [citado 2017 Nov 7];16(3):220-4. Disponible 
en: http://www.ncbi.nlm.nih.gov/ pubmed/22456776

75. Fishbane S, Pollack S, Feldman $\mathrm{HI}$, Joffe MM. Iron indices in chronic kidney disease in the National Health and Nutritional Examination Survey 1988-2004. Clin J Am Soc Nephrol [Internet]. 2009 Jan 1 [citado 2017 Nov 20];4(1):57-61. Disponible en: http://www.ncbi.nlm.nih.gov/pubm ed/18987297

76. Martínez-Castelao A, Górriz JL, Portolés JM, De Alvaro F, Cases A, Luño J, et al. Baseline characteristics of patients with chronic kidney disease stage 3 and stage 4 in spain: the MERENA observational cohort study. BMC Nephrol [Internet]. 2011 Dec 5 [citado 2017 Nov 20];12(1):53. Disponible en: http://www.ncbi.nlm.ni h.gov/pubmed/21970625

77. Ma JZ, Ebben J, Xia H, Collins a J. Hematocrit level and associated mortality in hemodialysis patients. J Am Soc Nephrol. 1999;10(3):610-9.

78. Luo J, Jensen DE, Maroni BJ, Brunelli SM. Spectrum and burden of erythropoiesis-stimulating agent hyporesponsiveness among contemporary hemodialysis patients. Am J Kidney Dis [Internet]. $2016 \mathrm{Nov}$ [citado 2017 Nov 20];68(5):763-71. Disponible en: http://www.ncbi.nlm.ni h.gov/pubmed/27528373

79. Babitt JL. Mechanisms of anemia in CKD. Med Clin North Am. 2012;40(3):857-70.

80. Nemeth E, Rivera S, Gabayan V, Keller C, Taudorf S, Pedersen BK, et al. IL-6 mediates hypoferremia of inflammation by inducing the synthesis of the iron regulatory hormone hepcidin. J Clin Invest [Internet]. 2004 May 1 [citado 2017 Nov 20];113(9):1271-6. Disponible en: http://www.ncbi.nlm.nih.gov/pubm ed/15124018
81. Babitt JL, Lin HY. Molecular mechanisms of hepcidin regulation: Implications for the anemia of CKD. Am J Kidney Dis [Internet]. 2010 Apr [citado 2017 Nov 20];55(4):726-41. Disponible en: http://www.ncbi.nlm.ni h.gov/pubmed/20189278

82. Tessitore N, Girelli D, Campostrini $\mathrm{N}$, Bedogna V, Pietro Solero G, Castagna A, et al. Hepcidin is not useful as a biomarker for iron needs in haemodialysis patients on maintenance erythropoiesisstimulating agents. Nephrol Dial Transplant. 2010;25(12):3996-4002.

83. Thomas DW, Hinchliffe RF, Briggs C, Macdougall IC, Littlewood T, Cavill I, et al. Guideline for the laboratory diagnosis of functional iron deficiency. $\mathrm{Br} \mathrm{J}$ Haematol [Internet]. 2013 Jun [citado 2017 Nov 20];161(5):639-48. Disponible en: http://www.ncbi.nlm.ni h.gov/pubmed/23573815

84. Kalantar-Zadeh K, Kalantar-Zadeh $\mathrm{K}$, Lee $\mathrm{GH}$. The fascinating but deceptive ferritin: to measure it or not to measure it in chronic kidney disease? Clin J Am Soc Nephrol [Internet]. 2006 Sep 1 [citado 2017 Dec 24];1 Suppl 1(Supplement 1):S9-18. Disponible en: http://www.ncbi.nlm.ni h.gov/pubmed/17699375

85. Rambod M, Kovesdy CP, KalantarZadeh K. Combined high serum ferritin and low iron saturation in hemodialysis patients: The role of inflammation. Clin J Am Soc Nephrol [Internet]. 2008 Nov 1 [citado 2017 Nov 20];3(6):1691-701. Disponible en: http://www.ncbi.nlm.nih.gov/pubm ed/18922994

86. Chapter 1: Diagnosis and evaluation of anemia in CKD. Kidney Int Suppl [Internet]. 2012 Aug [citado 2017 Nov 20];2(4):288-91. Disponible en: http://www.ncbi.nlm.nih.gov/pubm ed/25018948 
87. Vaziri ND. Safety issues in iron treatment in CKD. Semin Nephrol [Internet]. 2016 Mar [citado 2017 Nov 20];36(2):112-8. Disponible en: http://www.ncbi.nlm.nih.gov/pubm ed/27236132

88. Stoves J, Inglis H, Newstead CG. A randomized study of oral vs intravenous iron supplementation in patients with progressive renal insufficiency treated with erythropoietin. Nephrol Dial Transplant. 2001;16(5):967-74.

89. Shepshelovich D, Rozen-Zvi B, Avni T, Gafter U, Gafter-Gvili A. Intravenous versus oral iron supplementation for the treatment of anemia in CKD: An updated systematic review and meta-analysis. Am J Kidney Dis [Internet]. $2016 \mathrm{Nov}$ [citado 2017 Nov 20];68(5):677-90. Disponible en: http://www.ncbi.nlm.ni h.gov/pubmed/27321965

90. Tomer A, Amir B, Alon G, Hefziba G, Leonard L, Anat GG. The safety of intravenous iron preparations: Systematic review and meta-analysis. Mayo Clin Proc. 2015;90(1):12-23.

91. Stancu S, Stanciu A, Zugravu A, Bârsan L, Dumitru D, Lipan M, et al. Bone marrow iron, iron indices, and the response to intravenous iron in patients with non-dialysis-dependent CKD. Am J Kidney Dis [Internet]. 2010 Apr [citado 2017 Nov 20];55(4):639-47. Disponible en: http://www.ncbi.nlm.ni h.gov/pubmed/20079959

92. Sanai T, Ono T, Fukumitsu T. Beneficial effects of oral iron in Japanese patients on hemodialysis. Intern Med [Internet]. 2017;56(18):2395-9. Disponible en: https://www.jstage.jst.g o.jp/article/internalmedicine/56/18/56

_8520-16/_article 